\title{
Assessing suitability of temperature-based reference evapotranspiration methods for semi-arid basin of Maharashtra
}

\author{
P.S. WABLE ${ }^{1^{*}}$, M.K. JHA ${ }^{2}$ and S.D. GORANTIWAR ${ }^{3}$ \\ International Crop Research Institute for the Semi-Arid Tropics, Hyderabad, India \\ ${ }^{2}$ Agricultural and Food Engineering Department, Indian Institute of Technology Kharagpur, India \\ ${ }^{3}$ Dr. A. S. College of Agricultural Engineering, Mahatma Phule Krishi Vidyapeeth, Rahuri, India \\ *Corresponding author email:pawan.wable@gmail.com
}

\begin{abstract}
FAO Penman-Monteith (FAO-PM) is deemed as a sole standard method for estimating reference evapotranspiration $\left(E T_{0}\right)$. However, limited availability of meteorological data at spatial and temporal scales restricts the application of this method. To address this issue, the FAO 56 experts suggested three methods when only maximum and minimum temperature data are available: (i) Temperature-based Penman-Monteith (PMT-1) method wherein $\mathrm{T}_{\text {dew }} \approx \mathrm{T}_{\text {min }}$ (ii) PMT-2 wherein $\mathrm{T}_{\text {dew }} \approx \mathrm{T}_{\text {min }}-2.5$, and (iii) Hargreaves method. These $E T_{0}$ methods were assessed for a semi-arid basin of Western India which lacks adequate climatic data. The performances of the $\mathrm{ET}_{0}$ methods were evaluated against the standard FAO-PM method using salient statistical and graphical indicators, together with the sensitivity analysis. The results of the three temperature-based methods had a tendency of over-predication of $E T_{0}$ in the study area. The PMT-1 method, however, provided superior ET。 estimates compared to PMT-2 and Hargreaves methods. For estimating monthly $\mathrm{ET}_{\text {o }}$, the FAO-PM method was most sensitive to temperature. Further, $\mathrm{ET}_{0}$ of the monsoon season over the study area increased from 5 to $12 \%$ during 'drought' years compared to 'normal' years. It was concluded that PMT-1 method is the most suitable temperature-based method for estimating $\mathrm{ET}_{0}$ in semi-arid regions under limited climatic condition.
\end{abstract}

Keywords: FAO Penman-Monteith method, temperature-based Penman-Monteith method, Hargreaves method, ET mapping, limited data, semi-arid region

Evapotranspiration (ET) is one of the important components of the water cycle and plays a central role in water balance studies, hydrological modelling, planning and management of irrigation and drainage systems as well as in climatological studies. Crop Evapotranspiration $\left(\mathrm{ET}_{\mathrm{c}}\right)$ is affected by the crop characteristics, soil factors and climatic parameters, and management practices leading to a high spatial and temporal variability in $\mathrm{ET}_{\mathrm{c}}$ (Allen et al., 1998). The concept of reference evapotranspiration $\left(\mathrm{ET}_{\mathrm{o}}\right)$ evolved in the last decade of the $20^{\text {th }}$ century to study the evaporative demand of the atmosphere independently of crop type, crop development and management practices. $\mathrm{ET}_{0}$ is a climate parameter because it is only affected by climatic factors. The best estimates of $\mathrm{ET}_{\mathrm{o}}$ is done by using lysimeter but it is cumbersome, time consuming, costly, and its application at a larger scale is restricted. To overcome this problem, numerous empirical methods have been developed during past six decades for estimating $\mathrm{ET}_{\mathrm{o}}$ indirectly under varying agroclimatic conditions (Tabari et al., 2013; Jadhav et al., 2015; Phad et al., 2019). These methods can be classified into four groups (Jensen, 1990) of temperature-based methods
(Thornthwaite and Hargreaves, etc.), radiation-based methods (Priestley-Taylor, and FAO-24 radiation, etc.), pan methods (Christiansen Pan and FAO-24 pan), and combination methods (Penman-Monteith, and FAO-24 corrected Penman, etc.). Among these methods, FAO Penman-Monteith (FAOPM) has emerged as the sole standard method for $\mathrm{ET}_{\text {。 }}$ computation (Allen et al., 1998). Also, it can be applied in data-scarce situations.

Unfortunately, the application of FAO-PM method requires several meteorological data, some of them are missing or limited in spatial and temporal scales mostly in developing countries. According to the modern guidelines for computing crop water requirements (Allen et al., 1998), the following three methods can be used under data-scarce conditions: (i) Temperature-based Penman-Monteith (PMT-1) method, wherein $\mathrm{T}_{\text {dew }} \approx \mathrm{T}_{\text {min }}$; (ii) PMT-2, wherein $\mathrm{T}_{\text {dew }} \approx \mathrm{T}_{\text {min }}$-2.5; and (iii) Hargreaves method. Among the less data-intensive $\mathrm{ET}_{\mathrm{o}}$ methods used, temperature-based Hargreaves method has been found to be the best in arid and/or semi-arid climate of Spain (Lopez-Urrea et al., 2006), Iran (Tabari, 2010, Sabziparvar and Tabari, 2010), and India (Nandagiri and 
Kovoor, 2006; Meshram et al., 2013). In the recent past, a few researchers have evaluated the performance of temperaturebased Penman-Monteith and Hargreaves methods and reported contradictory results. In the semi-arid climate of Tunisia, the Hargreaves method outperformed compared to the PMT-1 method (Jabloun and Sahli, 2008). Sentelhas et al. (2010) reported that adjusted Hargreaves method can be preferred over the PMT-1 method in Canada. In semi-arid climate of Mediterranean countries (Todorovic et al., 2013) both PMT-1 and PMT-2 methods performed better than the Hargreaves. Based on the review, it can be concluded that the comparative evaluation of $\mathrm{ET}_{\mathrm{o}}$ estimation methods has attracted the attention of researchers and also only few studies (Nandagiri and Kovoor, 2006; Meshram et al., 2013) have been conducted in the Indian subcontinent related to the performance evaluation of $\mathrm{ET}_{\mathrm{o}}$ methods under limited data conditions, particularly in arid regions. Considering this research gap and an increasing incidence of drought (hydrological disaster) in several parts of India in general and Maharashtra in particular, the present study was conceived taking Sina River basin as study area. It suffers from severe water scarcity due to frequent droughts. Therefore, this study was carried out with the objectives to: (i) explore the efficacy of three methods for one meteorological station having all desirable climatic data and to find out a suitable method for other weather stations of the basin having limited data, (ii) quantify the sensitivity of $\mathrm{ET}_{\mathrm{o}}$ estimates to the meteorological parameters, and (iii) analyse spatio-temporal variation of $\mathrm{ET}_{\mathrm{o}}$ over the basin.

\section{MATERIALS AND METHODS}

\section{Study area and data collection}

Sina river basin (study area) is located between $17^{\circ} 28^{\prime}$ $\mathrm{N}$ and $19^{\circ} 16^{\prime} \mathrm{N}$ latitude, $74^{\circ} 28^{\prime} \mathrm{E}$ and $76^{\circ} 7^{\prime} \mathrm{E}$ longitude. The study area is of $12,707 \mathrm{~km}^{2}$ area, with an elevation ranging from 420 to $964 \mathrm{~m}$ MSL. More information regarding the study area can be gathered from Wable and Jha (2017). The data used in this study were collected from various government organizations. Fig. 1 shows the locations of the meteorological stations. Out of the four meteorological stations (Kashti, Rahuri, Rosa and Solapur), only Solapur station records all the meteorological data (maximum and minimum temperatures, wind speed, relative humidity and sunshine hour) on a daily basis required for the FAO-PM method for the period 2001-2005. Unfortunately, only temperature (minimum and maximum) data on a daily time scale were available at all stations for the period 1985-2009.
The meteorological data of Solapur station were collected from the India Meteorology Department, Pune. Temperature data of Kashti and Rosa meteorological stations were collected from the State Data Storage Centre, Nashik, and that for the Rahuri meteorological station was acquired from Mahatma Phule Agricultural University, Rahuri.

\section{Estimation of ET o}

\section{FAO-PM method}

The FAO Penman-Monteith (FAO-PM) equation was developed to describe ET of a reference grass crop, which is defined as the potential rate of evapotranspiration from a hypothetical crop with an assumed fixed height (120 mm), surface resistance (70 s.m $\mathrm{m}^{-1}$ ) and albedo (0.23), closely resembling the evapotranspiration from an extensive surface of a disease-free green grass cover of uniform height, actively growing, completely shading the ground, and with adequate water and nutrient supply (Allen et al., 1998).

The FAO-PM equation for the calculation of $\mathrm{ET}_{\mathrm{o}}$ takes the form:

$\mathrm{ET}_{\mathrm{o}}=\frac{0.408 \Delta\left(R_{n}-G\right)+\gamma \frac{900}{\overline{\mathrm{T}}+273} \mathrm{u}_{2}\left(\mathrm{e}_{\mathrm{s}}-\mathrm{e}_{\mathrm{a}}\right)}{\Delta+\gamma\left(1+0.34 \mathrm{u}_{2}\right)}$

Where $\mathrm{ET}_{\mathrm{o}}=$ Reference evapotranspiration, $\mathrm{mm} \mathrm{day}^{-1}$, $\mathrm{R}_{\mathrm{n}}=$ Net radiation at crop surface, $M \mathrm{MJm}^{-2}$ day $^{-1}, \mathrm{G}=$ Soil heat flux density, $\mathrm{MJm}^{-2}$ day $^{-1}, \mathrm{~T}=$ Mean daily air temperature at 2 $\mathrm{m}$ height, ${ }^{\circ} \mathrm{C}, \mathrm{u}_{2}=$ Wind speed at $2 \mathrm{~m}$ height, $\mathrm{m} \mathrm{s}^{-1}, \mathrm{e}_{\mathrm{s}}=$ Saturation vapour pressure, $\mathrm{kPa}, \mathrm{e}_{\mathrm{a}}=$ Actual vapour pressure, $\mathrm{kPa}, \mathrm{e}_{\mathrm{s}}-\mathrm{e}_{\mathrm{a}}=$ Saturation vapour pressure deficit, $\mathrm{kPa}, \Delta=$ Slope of vapour pressure curve, $\mathrm{kPa}{ }^{\circ} \mathrm{C}^{-1}$, and $\mathrm{g}=$ Psychometric constant, $\mathrm{kPa}^{\circ} \mathrm{C}^{-1}$.

\section{Estimation of ET $_{\text {o }}$ under data-scarce condition}

As mentioned earlier, limited climatic data were available for Kashti, Rosa, and Rahuri meterological stations in the study area. Hence, ET $_{\mathrm{o}}$ for these stations were estimated in this study by using the following temperature-based methods mentioned below.

\section{(a) PMT method}

FAO Penman-Monteith method requires a number of weather parameters for $\mathrm{ET}_{\mathrm{o}}$ calculation, which were not available for all stations. Hence, the recommendation of the procedure made by Allen et al. (1998) to estimate missing climatic parameters for the data sets (i.e., data of Kashti, Rahuri, Solapur and Rosa stations) containing at least maximum and minimum temperatures was followed to use 
the FAO-PM method.

Radiation under data scared environment is calculated by Eq.2. This relationship is known as Hargreaves' radiation formula (Allen et al., 1998), and is expressed as follows:

$\mathrm{R}_{\mathrm{s}}=\mathrm{K}_{\mathrm{RS}} \sqrt{\left(\mathrm{T}_{\max }-\mathrm{T}_{\min }\right) \mathrm{R}_{\mathrm{a}}}$

Where, $\mathrm{R}_{\mathrm{a}}=$ Extraterrestrial radiation, $\mathrm{MJm}^{-2}$ day $^{-1} ; \mathrm{T}_{\max }$ $\& \mathrm{~T}_{\min }=$ Maximum and minimum air tempertures, ${ }^{\circ} \mathrm{C}$, and $\mathrm{K}_{\mathrm{RS}}=$ Adjustment coefficient (for interior locations, $\mathrm{K}_{\mathrm{RS}}$ is 0.16 ).

Wind speed is estimated as the variation in average wind speed over monthly periods. FAO 56 suggests its range from less than $1 \mathrm{~m} . \mathrm{s}^{-1}$ (light wind areas) to greater than $5 \mathrm{~m} . \mathrm{s}^{-1}$ (strong wind areas). The average value of wind speed at $2 \mathrm{~m}$ height for over 2000 weather stations across the globe was found to be $2 \mathrm{~m} \mathrm{~s}^{-1}$ (Allen et al., 1998), which was considered for the Solapur station to evaluate temperature-based FAOPM methods considered in this study.

For the missing humidity is calculated by using Eq. 3 . In this case, $\mathrm{e}_{\mathrm{a}}$ is calculated as (Allen et al., 1998):

$\mathrm{e}_{\mathrm{a}}=e^{o}\left(\mathrm{~T}_{\min }\right)=0.611 \exp \left(\frac{17.27 \mathrm{~T}_{\min }}{\mathrm{T}_{\min }+237.3}\right)$

The relation $\mathrm{T}_{\text {min }} \approx \mathrm{T}_{\text {dew }}$ (dew pint temperature) holds good for well-watered locations. In arid regions, $\mathrm{T}_{\text {min }}>\mathrm{T}_{\text {dew }}$ therefore, Allen et al. (1998) suggested that $\mathrm{T}_{\mathrm{dew}}$ may be better approximated by subtracting $2-3^{\circ} \mathrm{C}$ from $\mathrm{T}_{\min }$ as a correction for arid regions. To verify this suggestion, two cases of $\mathrm{ET}_{\mathrm{o}}$ estimation were considered in this study, namely PMT-1 wherein $\mathrm{T}_{\mathrm{dew}} \approx \mathrm{T}_{\text {min }}$ and PMT-2 wherein $\mathrm{T}_{\mathrm{dew}} \approx \mathrm{T}_{\text {min }}-2.5^{\circ} \mathrm{C}$.

\section{(a) Hargreaves method}

As an alternative to the FAO-PM method, Allen et al. (1998) suggested to use the Hargreaves method for estimating $\mathrm{ET}_{\mathrm{o}}$ under data limited conditions, which requires measured maximum and minimum temperature data only. The Hargreaves equation is given as (Hargreaves and Samani, 1985):

$\mathrm{ET}_{\mathrm{o}}=0.0023 \mathrm{R}_{\mathrm{a}}\left(\mathrm{T}_{\text {mean }}+17.8\right)\left(\mathrm{T}_{\max }-\mathrm{T}_{\min }\right)^{0.5}$

In Eq. (4), the units of both $\mathrm{ET}_{\mathrm{o}}$ and $\mathrm{R}_{\mathrm{a}}$ are $\mathrm{mm}_{\text {day }}{ }^{-1}$. It has a tendency to under-predict $\mathrm{ET}_{\mathrm{o}}$ under high wind conditions $\left(\mathrm{u}_{2}>3 \mathrm{~m} \cdot \mathrm{s}^{-1}\right)$, and to over-predict $\mathrm{ET}_{\mathrm{o}}$ under the conditions of high relative humidity (Allen et al., 1998).

\section{Performance evaluation of ET $T_{o}$ methods}

The results of $\mathrm{ET}_{\mathrm{o}}$ estimated under limited data conditions by the three methods (PMT-1, PMT-2 and Hargreaves) were compared with the FAO-PM method. The performance evaluation of these $\mathrm{ET}_{\mathrm{o}}$ estimation methods was done using five statistical indicators, viz., Mean Absolute Error (MAE), Root Mean Squared Error (RMSE), Nash-Sutcliffe efficiency (NSE), Index of Agreement (IOA), and Percent Bias (PBIAS). Apart from these statistical indicators, a visual comparison of the $\mathrm{ET}_{\mathrm{o}}$ estimated by the FAO-PM method with the $\mathrm{ET}_{\mathrm{o}}$ estimated with missing data procedures was also performed using scatter plots.

\section{Sensitivity analysis}

In this study, the sensitivity analysis of FAO-PM ET。 estimates was carried out on a monthly basis at Solapur station during 2001-2005. For this weather station, four key climatic parameters (mean temperature: $\mathrm{T}_{\text {mean }}$, mean relative humidity: $\mathrm{RH}_{\text {mean }}$, wind speed: $\mathrm{u}_{2}$, and sunshine hours: $\mathrm{S}_{\text {sh }}$ ) were changed within $\pm 20 \%$ at intervals of $5 \%$. Thereafter, the percentage change from the original $\mathrm{ET}_{\mathrm{o}}$ estimate was calculated, and the sensitivity curves were plotted.

\section{ET $T_{o}$ mapping}

Spatial variation of $\mathrm{ET}_{\mathrm{o}}$ was analyzed by generating $\mathrm{ET}_{\mathrm{o}}$ maps using ArcGIS. Thiessen polygon method was used for $\mathrm{ET}_{\mathrm{o}}$ mapping because of less number of meteorological stations in the study area (Maidment, 1992). The analysis of annual spatio-temporal variability of $\mathrm{ET}_{\mathrm{o}}$ estimates over the study area for the period 1985-2009 was carried out by estimating $\mathrm{ET}_{\mathrm{o}}$ at each station by using the best performing temperature-based method. Further, the spatial variability of $\mathrm{ET}_{\mathrm{o}}$ was mapped using Thiessen polygon method. This analysis was performed by considering the $\mathrm{ET}_{\mathrm{o}}$ estimates for the monsoon season (June to October period), as most of the crops are grown in this season. As the study area was affected by drought in 2003 (EIS, 2006) therefore, ET maps were generated for monsoon seasons of 'drought' and 'normal' years. The year 2009 was considered as a representative of normal years.

\section{RESULTS AND DISCUSSION}

\section{Performance of ET methods}

Performance evaluation of the three temperature-based methods for estimating $\mathrm{ET}_{\mathrm{o}}$ relative to standard FAO-PM at Solapur station for 2001-2005 period was carried out using five statistical indicators as presented in Table 1. It can be inferred that all five statistical indicators support PMT-1 as a best method with lowest values of RMSE $\left(0.70 \mathrm{~mm}\right.$ day $\left.^{-1}\right)$, MAE (0.59 mm day $\left.{ }^{-1}\right)$, PBIAS (7.87\%) and highest value of 
Table 1: Statistical summary of different ET $_{\mathrm{o}}$ methods with reference to FAO-PM on monthly time step for Solapur Station

\begin{tabular}{llccccc}
\hline Sl. No. & \multicolumn{1}{c}{ Method } & $\begin{array}{c}\text { MAE, } \\
\mathrm{mm} \mathrm{day}^{-1}\end{array}$ & $\begin{array}{c}\text { RMSE, } \\
\mathrm{mm} \mathrm{day}^{-1}\end{array}$ & NSE & IOA & $\begin{array}{c}\text { PBIAS } \\
\%\end{array}$ \\
\hline 1. & PMT-1 & $0.59^{*}$ & $0.70^{*}$ & $0.66^{*}$ & $0.89^{*}$ & $-7.87^{*}$ \\
2. & PMT-2 & $0.80^{\#}$ & $0.93^{\#}$ & $0.40^{\#}$ & $0.84^{\#}$ & $-15.55^{\#}$ \\
3. & Hargreaves & 0.71 & 0.84 & 0.51 & 0.87 & -14.07 \\
\hline
\end{tabular}

$\operatorname{NSE}(0.66)$ and IOA(0.89).

Moreover, comparison of the $\mathrm{ET}_{\mathrm{o}}$ estimated by FAOPM and other temperature-based methods was performed using scatter plot at Solapur station (Fig. 1). It is apparent from this figure that PMT-1 provides better results compared to other two temperature based methods, which confirms finding of statistical indicators. Among the methods examined, the performance of PMT-2 method was the worst (Table 1). Furthermore, negative PBIAS values (Table 1) revealed that all three less data-intensive methods had tendency to overpredict monthly $\mathrm{ET}_{0}$ estimates with lowest PBIAS value (7.87\%) for PMT-1 method. It could be inferred that the PMT1 method was most suitable for estimating $\mathrm{ET}_{0}$ for the study area when only temperature data are available. This finding is consistent with the results obtained by Todorovic et al. (2013) for the semi-arid regions of Mediterranean countries. It should be noted that the aridity correction $\mathrm{T}_{\mathrm{dew}} \approx \mathrm{T}_{\min }-2.5$ suggested by Allen et al. (1998) for arid regions does not hold good for the river basin under study. Also, performance of Hargreaves method in this study was contrary to that reported in Allen et al.(1998).

\section{Sensitivity analysis}

Monthly ET or Solapur station was estimated using FAO-PM method. At this station, the extent of change in $\mathrm{ET}_{\text {。 }}$ with respect to $5 \%$ to $20 \%$ (increase and decrease) in each climatic variables $\left(\mathrm{T}_{\text {mean, }}, \mathrm{RH}_{\text {mean, }}, \mathrm{u}_{2}\right.$, and $\left.\mathrm{S}_{\mathrm{sh}}\right)$ on monthly time scale during 2001-2005 were performed and is presented in Fig. 2. The slope of the sensitivity curves of ET 0 climatic variables were positive for $\mathrm{T}_{\text {mean }}, \mathrm{u}_{2}$ and $\mathrm{S}_{\mathrm{sh}}$, whereas negative for $\mathrm{RH}_{\text {mean }}$. Also, the change in temperature had the highest effect on $\mathrm{ET}_{0}$ ranging from (- ) $15 \%$ to $16 \%$ for $( \pm) 20 \%$ variation in the temperature, followed by relative humidity and sunshine hours, both within the range of $( \pm$ ) $6 \%$. Thus, sensitivity analysis indicated that a change in wind speed had the least impact on the $\mathrm{ET}_{0}$ estimation $( \pm) 5 \%$ as compared to other
Table 2: Trends of annual $\mathrm{ET}_{\mathrm{o}}$ at different stations during 1985-2009

\begin{tabular}{ll}
\hline Stations & Trend equation \\
\hline Kashti & $\mathrm{Y}=-11.336 \mathrm{X}+1925.3$ \\
Rahuri & $\mathrm{Y}=2.465 \mathrm{X}+1784.3$ \\
Rosa & $\mathrm{Y}=1.745 \mathrm{X}+1692.6$ \\
Solapur & $\mathrm{Y}=2.147 \mathrm{X}+1808.1$ \\
\hline
\end{tabular}

weather parameters. The mean temperature of the station thus was the most sensitive parameter to monthly $\mathrm{ET}_{0}$ estimation

\section{Spatio-temporal variability of ET}

The spatio-temporal variability of ET during 19852009 period was studied using best performed PMT-1 method. The annual trends of $\mathrm{ET}_{\mathrm{o}}$ at four stations are given in Table 2. The trend analysis indicated that $\mathrm{ET}_{0}$ was decreasing at rate of $11 \mathrm{~mm}$ year $^{-1}$ in Kashti station and it was found to increase at Rahuri, Rosa and Solapur stations at the rates of 2.47, 1.75, $2.15 \mathrm{~mm}$ year $^{-1}$, respectively.

The spatial variation of $\mathrm{ET}_{0}$ during monsoon season over the study area for normal and drought years using Thiessen polygon method is shown in Figs. 5(a,b). The average $\mathrm{ET}_{0}$ during monsoon season (June-October) varied from $3.8 \mathrm{~mm}$ day $^{-1}$ to $4.7 \mathrm{~mm}$ day $^{-1}$ in normal years [Fig. 3(a)], whereas it varied from $4.0 \mathrm{~mm}$ day ${ }^{-1}$ to $5.0 \mathrm{~mm}_{\text {day }}{ }^{-1}$ in drought years [Fig. 3(b)]. In northern, southern and the north-western part of the study area, there was an increase in $\mathrm{ET}_{0}$ estimate from 4 to $6 \%$ during drought years, encompassing about $50 \%$ of the study area $\left(6132 \mathrm{~km}^{2}\right)$. On the other hand, the maximum increase in $\mathrm{ET}_{\mathrm{o}}$ for the remaining $50 \%$ of the study area covering the central portion was found to be $12 \%$ in drought years as compared to normal years. This mainly covered Bhoom, Jamkhed, Barshi, Madha, Karmala and Parenda blocks of the study area [Figs. 3(a,b)]. 

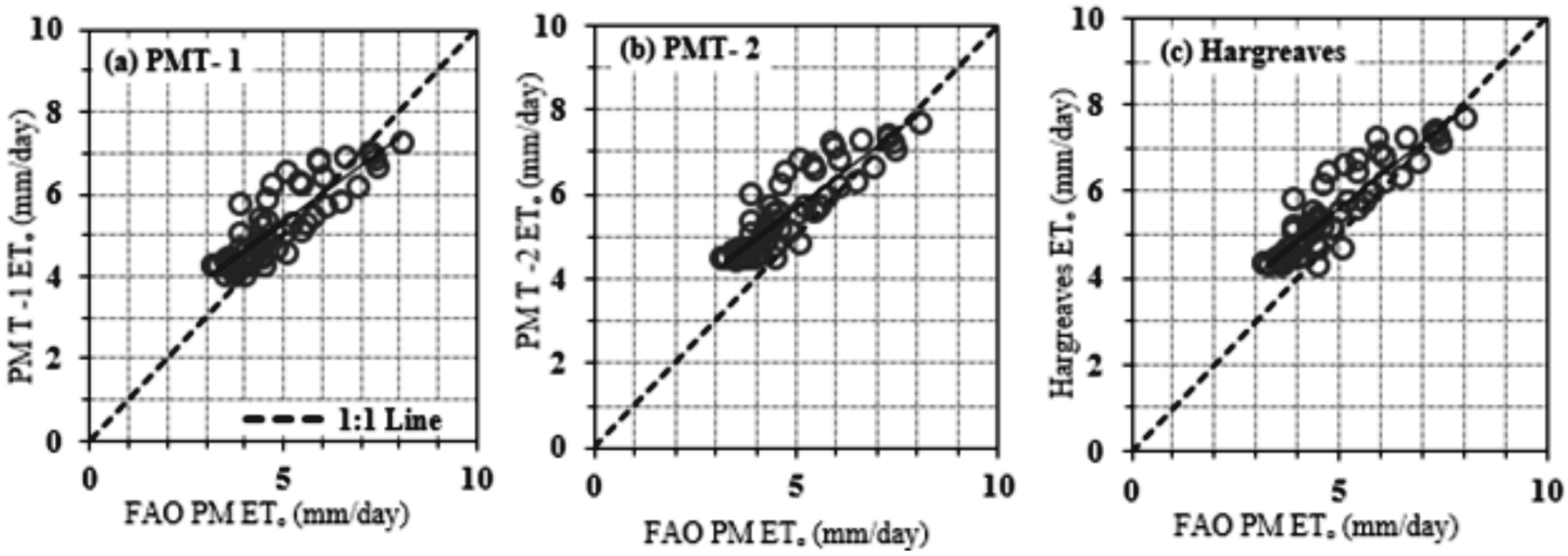

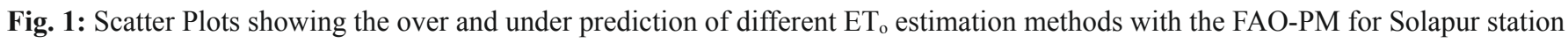

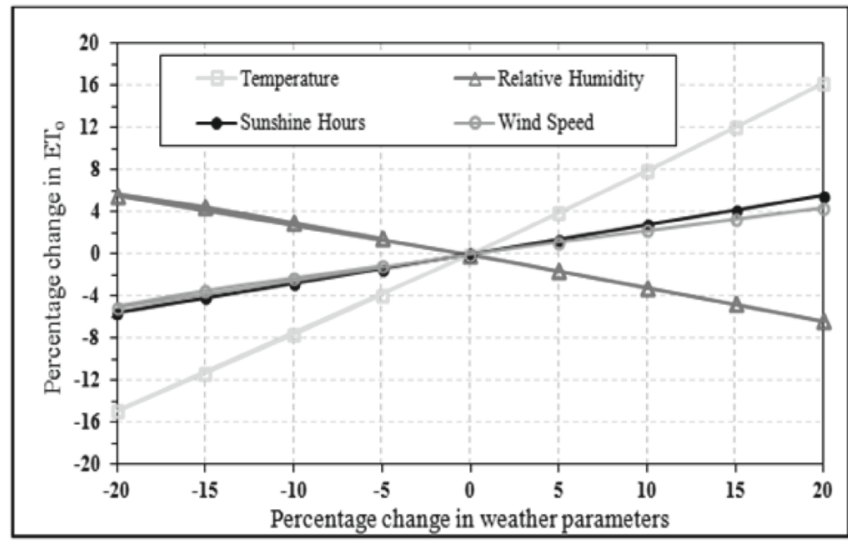

Fig. 2: Percentage change in $\mathrm{ET}_{\mathrm{o}}$ due to changes in weather parameters at Solapur weather station on monthly time scale

\section{CONCLUSIONS}

This study focuses on the performance evaluation of three temperature-based $\mathrm{ET}_{\mathrm{o}}$ methods (PMT-1, PMT-2 and Hargreaves) with reference to the standard FAO-PM method under data-scarce conditions in a semi-arid river basin of western India. Among the three temperature-based methods,

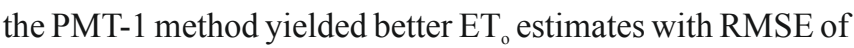
$0.59 \mathrm{~mm}$ day $^{-1}$ and IOA of 0.89 . The spatial variation of $\mathrm{ET}_{\mathrm{o}}$ in the study area during the monsoon season ranged from 3.8-4.7 $\mathrm{mm}$ day $^{-1}$ for normal years, and 4.0-5.0 $\mathrm{mm}$ day $^{-1}$ for drought years. The maximum increase in $\mathrm{ET}_{\mathrm{o}}$ during drought years was $12 \%$ as compared to normal years in half of the study area. This finding emphasizes the urgent need for efficient management of water resources to ensure sustainable water supply during drought years for domestic and agriculture purposes. The developed $\mathrm{ET}_{\mathrm{o}}$ maps can provide a scientific basis for effective planning and management of water resources at a micro-scale (block or district level) in the study area under scanty climatic
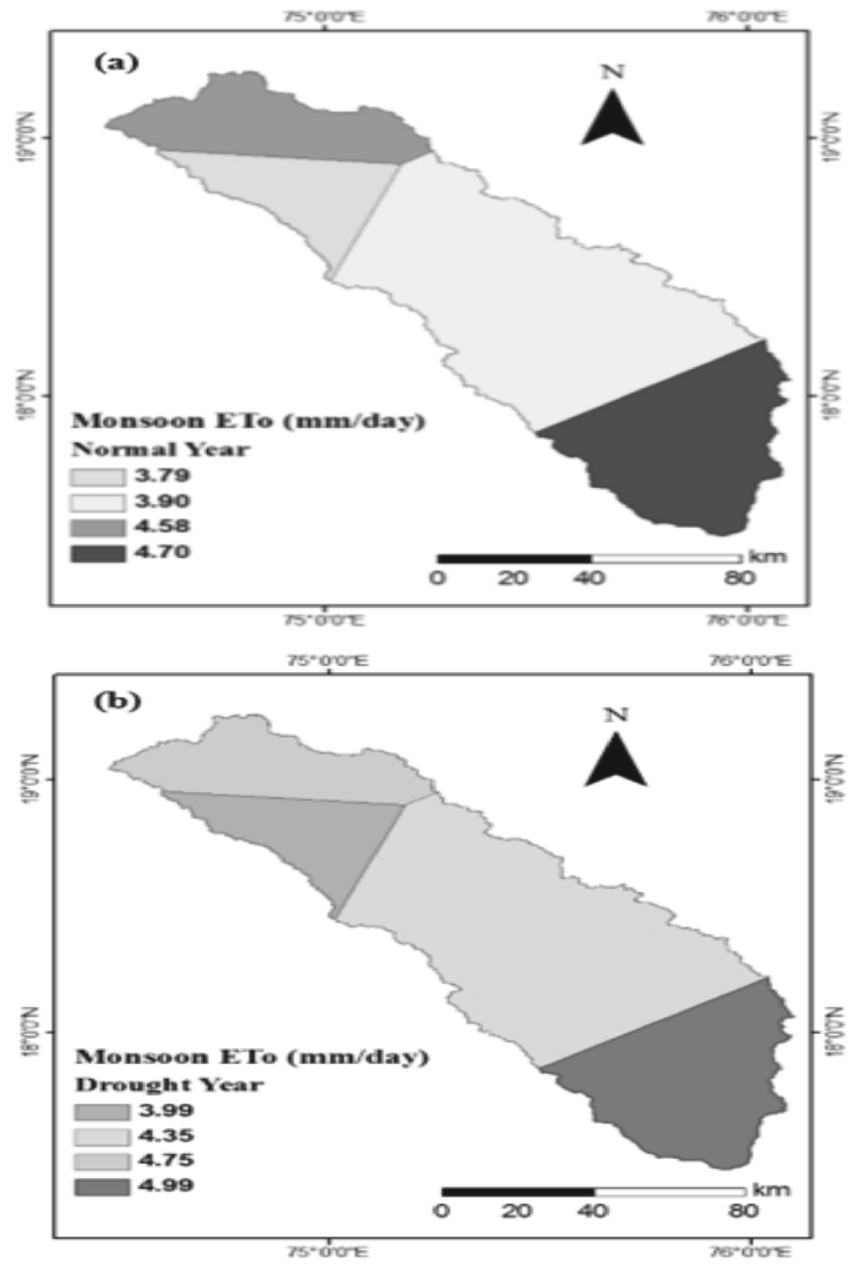

Fig. 3 : Spatial variation $\mathrm{ET}_{\mathrm{o}}$ over the study area during (a) Normal year and (b) Drought year

data conditions. The methodology presented in this study can provide useful guidelines for semi-arid regions of Indian subcontinent as well as for other regions of the world. 


\section{REFERENCES}

Allen, R.G., Perevia L.S, Raes, D. and Smith, M. (1998). Crop Evapotranspiration: Guidelines for Computing Crop Water Requirements. FAO Irrigation and Drainage Paper No. 56, Food and Agriculture Organization, Rome, Italy, pp: 300.

EIS (2006). Disaster Management in Maharashtra. Environmental Information System (EIS). Environmental Department, Environmental Information System (ENVIS) Newsletter, Government of Maharashtra, India, 1, pp: 1-10.

Hargreaves, G.H. and Samani, Z.A. (1985). Reference crop evapotranspiration from temperature. Appl. Eng. Agric., 1(2): 96-99.

Jabloun, M.D. and Sahli, A. (2008). Evaluation of FAO-56 methodology for estimating reference evapotranspiration using limited climatic data: Application to Tunisia. Agric. Water Manage., 95(6): 707-715.

Jadhav, P.B., Kadam, S.A. and Gorantiwar, S.D. (2015). Comparison of methods for estimating reference evapotranspiration $\left(\mathrm{ET}_{\mathrm{o}}\right)$ for Rahuri region. $J$. Agrometeorol., 17(2): 204-207.

Jensen, M.E., Burman, R.D. and Allen, R.G. (1990). Evapotranspiration and Irrigation Water Requirements. ASCE Manual and Report on Engineering Practices No. 70, ASCE, New York, pp: 528.

Lopez-Urrea, R., de Santa Olalla, F.M., Fabeiro, C. and Moratalla, A. (2006). Testing evapotranspiration equations using lysimeter observations in a semiarid climate. Agric. Water Manage., 85(1): 15-26.

Maidment, D.R. (1992). Handbook of Hydrology. McGrawHill, Inc., New York, USA, pp: 1424.

Meshram, D.T., Gorantiwar, S.D., Mittal, H.K. and Singh,
N.V. (2013). Computation of reference crop evapotranspiration of Nasik station of Maharashtra, India. Mausam, 64(2): 357-362.

Nandagiri, L. and Kovoor, G.M. (2006). Performance evaluation of reference evapotranspiration equations across a range of Indian climates. J. Irrig. Drain. Eng., 132(3): 238-249.

Phad, S.V., Dakhore, K.K. and Sayyad, R.S. (2019). Comparison of different methods for estimation of reference evapotranspiration at Parbhani, Maharashtra. J. Agrometeorol., 21(2): 236-238.

Sabziparvar, A.A. and Tabari, H. (2010). Regional estimation of reference evapotranspiration in arid and semiarid regions. J. Irrig. Drain. Eng., ASCE, 136(10): 724-731.

Sentelhas, P.C., Gillespie, T.J. and Santos, E.A. (2010). Evaluation of FAO Penman-Monteith and alternative methods for estimating reference evapotranspiration with missing data in Southern Ontario, Canada. Agric. Water Manage., 97(5): 635-644.

Tabari, H. (2010). Evaluation of reference crop evapotranspiration equations in various climates. Water Resour. Manage., 24(10): 2311-2337.

Tabari, H., Grismer, M.E. and Trajkovic, S. (2013). Comparative analysis of 31 reference evapo transpiration methods under humid conditions. Irrig. Sci., 31(2): 107-117.

Todorovic, M., Karic, B. and Pereira, L.S. (2013). Reference evapotranspiration estimate with limited weather data across a range of Mediterranean climates. J. Hydrol., 481: 166-176.

Wable, P.S. and Jha, M.K. (2017). Application of Archimedean copulas to the impact assessment of hydro-climatic variables in semi-arid aquifers of western India. Hydrogeol J., 26(1): 89-108. 